\title{
Макрофауна беспозвоночных водной экосистемы участка «Острасьевы яры» государственного природного заповедника «Белогорье» по данным 2004-2007 гг.
}

\author{
А.Е. Силина ${ }^{1}$, И.А. Будаева ${ }^{2}$, Е.Ю. Аникеенко ${ }^{1}$ \\ ${ }^{1}$ Государственный природный заповедник «Белогорье», \\ Россия, 309342, Белгородская обл., п. Борисовка, пер. Монастырский, д. 3 \\ ${ }^{2}$ Воронежский государственный университет, \\ Россия, 394018, г. Воронеж, Университетская пл., 1 \\ E-mail: allasilina@list.ru; irbudaeva@yandex.ru
}

\begin{abstract}
Аннотация. Водная экосистема участка «Острасьевы яры» государственного природного заповедника «Белогорье» относится к бассейну Днепра. Работа по инвентаризации фауны данной экосистемы начата авторами в 2004 году, поскольку родниково-ручьевые экосистемы Центрального Черноземья России до этого периода были недостаточно изученными, исследования здесь охватывали преимущественно бассейн Верхнего Дона. Целью данной работы было выявление видового состава, доминирующих видов и групп макрозообентоса и зоофитоса в различных участках русла ручья урочища Острасьевы яры. В результате исследований 20042007 гг. выявлено 135 видов беспозвоночных, из них в верховье - 53 вида, в среднем течении - 53, в низовье - 66. Доминировали насекомые, составившие $68,3 \%$ от числа собранных животных, среди которых наиболее массовыми были двукрылые и веснянки. Массовыми видами являлись моллюски Pseudeupera arcidens (Krivosheina, 1978) и веснянки Nemoura cinerea Retzius, 1783. Впервые для фауны Центрального Черноземья указаны 3 вида беспозвоночных: клещи Arrenurus mulleri Koenike, 1901 и психодиды (двукрылые) - Satchelliella trivialis (Eaton, 1893) и Ulomyia cognata (Eaton, 1893). В последнее десятилетие на участке «Острасьевы яры» активизировалась деятельность бобра, что привело к значительным изменениям родниково-ручьевой системы. Поэтому полученные данные в исследовании 2004-2007 гг. могут быть использованы в качестве фоновых при оценке зоогенного влияния на макрозообентос родниково-ручьевой экосистемы.
\end{abstract}

Ключевые слова: водные беспозвоночные, олигохеты, пиявки, моллюски, клещи, насекомые.

Для цитирования: Силина А.Е., Будаева И.А., Аникеенко Е.Ю. 2021. Макрофауна беспозвоночных водной экосистемы участка «Острасьевы яры» государственного природного заповедника «Белогорье» по данным 2004-2007 гг. Полевой журнал биолога, 3 (3): 270-283. DOI: $10.52575 / 2658-3453-2021-3-3-270-283$

\section{Macrofauna of Invertebrates in Aquatic Ecosystem of Site "Ostrasyevy Yary" of the Belogorye State Nature Reserve According to Data from 2004-2007}

\author{
Alla E. Silina ${ }^{1}$, Irina A. Budaeva ${ }^{2}$, Elena Yu. Anikeenko \\ ${ }^{1}$ Belogorye State Nature Reserve, \\ 3 Monastyrskiy Ln, Borisovka vill., Belgorod Region, 309340, Russia \\ ${ }^{2}$ Voronezh State University, \\ 1 Universitetskaya Sq., Voronezh, 394018, Russia \\ E-mail: allasilina@list.ru; irbudaeva@yandex.ru
}

Abstract. The aquatic ecosystem of the Ostrasyovy Yary site of the Belogorye State Nature Reserve belongs to the Dnieper basin. The work on the inventory of the fauna of this ecosystem was started by the 
authors in 2004, since the spring-stream ecosystems of the Central Chernozem Region of Russia were insufficiently studied before this period, research here mainly covered the Upper Don basin. The purpose of this work was to identify the species composition, dominant species and groups of macrozoobenthos and zoophytos in various parts of the streambed of the Ostrasyovy Yary tract. As a result of research in 2004-2007. 135 species of invertebrates were identified, including 53 species in the upper reaches, 53 in the middle reaches, and 66 in the lower reaches. Insects dominated, accounting for $68.3 \%$ of the collected animals, among which diptera and freckles were the most widespread. The mass species were the mollusks Pseudeupera arcidens (Krivosheina, 1978) and the freckles Nemoura cinerea Retzius, 1783. For the first time, 3 invertebrate species were indicated for the fauna of the Central Chernozem region: the mites Arrenurus mulleri Koenike, 1901 and the psychodids (diptera) - Satchelliella trivialis (Eaton, 1893) and Ulomyia cognata (Eaton, 1893). In the last decade, beaver activity has intensified at the Ostrasyovy Yary site, which has led to significant changes in the spring-stream system. Therefore, the data obtained in the 2004-2007 study can be used as background data for assessing the zoogenic effect on the macrozoobenthos of the spring-stream ecosystem.

Keywords: aquatic invertebrates, oligochaetes, leeches, mollusks, ticks, insects.

For citation: Silina A.E., Budaeva I.A., Anikeenko E.Yu. 2021. Macrofauna of Invertebrates in Aquatic Ecosystem of Site "Ostrasyevy Yary" of the Belogorye State Nature Reserve According to Data from 2004-2007. Field Biologist Journal, 3 (3): 270-283 (in Russian). DOI: $10.52575 / 2658-3453-2021-3-3-270-283$

Received July 9, 2021

\section{Введение}

Водная экосистема участка «Острасьевы яры» государственного природного заповедника «Белогорье», расположенная в пределах Днепровского бассейна, в начале XXI века представляла собой периодически прерывающуюся родниково-ручьевую систему с выходом ключей (лимнокрен), наличием родниковых топей в верховье ручья (гелокрен) и участков русла шириной до 1 м, чаще - 20-40 см, с выраженным течением (реокрен). Целью нашей работы в 2004-2007 гг. являлось выявление видового состава, доминирующих видов и групп макрозообентоса и зоофитоса в различных участках русла ручья заповедного участка «Острасьевы яры».

В период исследований (2004-2007 гг., сборы А.Е. Силиной и Е.Ю. Аникеенко) гидрофауна этого водотока была представлена преимущественно ручьевыми, родниковыми и полуводными формами, чаще криофильными либо эвритермными видами насекомых (веснянки, поденки, ручейники, двукрылые). В связи с активизацией в последнее десятилетие деятельности бобра водная экосистема урочища Острасьевы яры стала разнородной на различных участках яра. В результате зарегулирования стока ручья при строительстве бобровых плотин водная экосистема к настоящему времени претерпела существенные трансформации в связи с усложнением инфраструктуры бобровых угодий - и в облесенной, и в остепненной частях яра появились бобровые запруды, бобровые каналы, при этом само русло ручья, начиная с верховья, испытывает и биогенную, и гидродинамическую нагрузку, что проявляется в замедлении скорости течения на призапрудных участках, заилении русла и, как следствие, в обеднении и существенной смене экологического облика фаунистических комплексов, населяющих водоток.

Исследования родниковых и ручьевых экосистем европейской части России проводились рядом авторов преимущественно на территории Волжского речного бассейна - в Подмосковье [Чертопруд, 2006], Пензенской [Ивановский, 2010] и Самарской областях [Чужекова, 2015] и других. На территории Центрально-Черноземного региона (ЦЧР) России родниково-ручьевые экосистемы изучены недостаточно, исследования охватывали в основном бассейн Верхнего Дона [Силина, 2014a; Силина, Иванов, Григоренко, 2004]. Полученные нами данные в исследовании 2004-2007 гг. русла ручья заповедного участка «Остра- 
сьевы яры〉 могут быть использованы в качестве фоновых при оценке зоогенного влияния на макрозообентос родниково-ручьевой экосистемы.

\section{Объекты и методы исследования}

Исследуемая родниково-ручьевая система находится на дне степной балки в урочище Острасьевы яры - участок ГПЗ «Белогорье» (Борисовский район, Белгородская область, 50,554472 $\left.\mathrm{N}, 36,055798^{\circ} \mathrm{E}\right)$. Участок был организован в 1995 г., его площадь составляет 90 га. В верховье, в южной части, балка облесена, низовье (северная часть) упирается в искусственную прудовую экосистему на р. Гостинка - притоке р. Ворскла Днепровского речного бассейна [Решетникова, 2018].

Пробы отбирали гидробиологическим сачком и вручную с камней и погруженных веток 29.09.2004 (сборы А.Е. Силиной), а также 9.11.2005, 30.11.2005, 9.11.2006 и в период с 12.07.2007 по 12.10.2007 (сборы А.Ю. Аникеенко). Пробы промывали в лабораторных условиях. Определение материала велось по специальным ключам [Соколов, 1940; Тузовский 1990; Определитель..., 1994; Определитель..., 1997; Определитель..., 1999; Определитель..., 2001; Определитель..., 2004].

\section{Результаты исследования}

По данным 2004-2007 гг. (17 качественных сборов в 10 пунктах верховья, низовья и среднего течения ручья) население родниково-ручьевой экосистемы «Острасьев ручей» было представлено не менее чем 135 видами беспозвоночных из 4 типов, 8 классов, 16 отрядов и 45 семейств. Из них 116 видов обнаружены в живом виде, другие таксоны идентифицировали по домикам, раковинам либо головным капсулам. Малощетинковые черви (Oligochaeta) были представлены 6 видами, пиявки (Hirudinea) - 5 видами, волосатики (Nematomorpha) - 1 видом, моллюски (Mollusca) - 9 видами (14 с учетом раковин), из них 2 (3) вида двустворчатых (Bivalvia) и 7 (11) видов - брюхоногих (Gastropoda). По одному виду было отмечено в группах ракообразных, пауков и клещей. Наибольшим разнообразием отличались насекомые (Insecta) - 92 вида из 7 отрядов: ногохвостки (Collembola) 2 вида, веснянки (Plecoptera) - 7 видов, поденки (Ephemeroptera) - 2 вида, ручейники (Trichoptera) - 9 видов, клопы (Heteroptera) - 4 вида, жуки (Coleoptera) - не менее 18 видов, двукрылые (Diptera) - 50 видов. Среди двукрылых на стадиях личинки и куколки выявлено 14 видов короткоусых (Brachycera: семейства Stratiomyidae, Tabanidae, Ephydridae, Sciomyzidae, Syrphidae, Muscidae), 36 - длинноусых (Nematocera: семейства Ptychopteridae, Limoniidae, Sciaridae, Psychodidae, Dixidae, Culicidae, Simuliidae, Ceratopogonidae и Chironomidae). Наиболее разнообразны представители семейства Chironomidae - 20 видов: Tanypodinae -8 видов, Prodiamesinae - 1 вид, Orthocladiinae -2 вида, Chironominae -9 видов, из них 7 - из трибы Chironomini и 2 - из трибы Tanytarsini.

Численно доминирующей группой среди собранных беспозвоночных были насекомые, составившие 68,3\% от числа собранных животных. Среди них наиболее обильными являлись двукрылые (34,9 \%) при доминировании комаров-звонцов (16,5 \%), второстепенными - веснянки $(21,8$ \%). Субдоминантной группой по обилию были моллюски $(24,7 \%)$ при доминировании двустворчатых из семейства Euglesidae. На долю собранных экземпляров олигохет и пиявок приходится лишь 2,8 и 3,5 \% соответственно. Такие группы, как волосатики, ракообразные, пауки и клещи отмечены в сборах единичными экземплярами.

К массовым видам «Острасьева ручья» в период обследования 2004-2007 гг. отнесены мелкие двустворчатые моллюски Pseudeupera arcidens (Krivosheina, 1978) (22,1% от числа собранных беспозвоночных) - вид, характерный для ручьевых и холодноводных малых рек средней полосы, и веснянки Nemoura cinerea (Retzius, 1783) (19,0 \%) - наиболее эврибионтный представитель отряда, в условиях Центрального Черноземья предпочитающий холодноводные ручьи и верховья малых рек.

Относительно часто встречались земноводные комары - Dixella serotina (Meigen, 1818 ) (5,1 \%), реже - моллюски Planorbis planorbis (Linnaeus, 1758) (2,5\%), ручейники Ol- 
igostomis reticulata (Linnaeus, 1761) (3,3\%), личинки мух-львинок Oplodontha viridula (Fabricius, 1775) (3,0 \%), комары-звонцы Xenopelopia falcigera (Kieffer, 1911) (3,6 \%) и Microtendipes pedellus (De Geer, 1776) (2,7\%).

К широко распространенным в пределах ручьевой экосистемы участка «Острасьевы яры» отнесены: тельматофильный вид брюхоногих моллюсков P. planorbis (встречался в 66,7 \% проб), ручейники Beraea pullata (Curtis, 1834) (53,3\% с учетом домиков). В меньшей мере, почти в половине отобранных проб, отмечены львинки O. viridula, pyчейники O. reticulata, комары-звонцы Conchapelopia melanops (Wiedemann, 1818) (по $46,7 \%)$, веснянки $N$. cinerea (40,0\%). В трети от общего числа проб отмечены виды малощетинковых червей Lumbriculus variegatus (Müller, 1773), пиявки Glossiphonia heteroclita (Linnaeus, 1761), моллюски P. arcidens, Lymnaea palustris (Müller, 1774), двукрылые - Eleophila submarmorata (Verrall, 1887), Satchelliella trivialis (Eaton, 1893), Apsectrotanypus trifascipennis (Zetterstedt, 1835).

В верховье ручья нами было выявлено 53 вида беспозвоночных, при этом наибольшего разнообразия здесь достигают малощетинковые черви, веснянки, жесткокрылые, комары-звонцы из подсемейства Tanypodinae. Доминирование видов и групп в верховье выражено более резко. Доминировали мелкие моллюски P. arcidens и веснянки N. cinerea. В значимом количестве были выявлены черви Limnodrilus hoffmeisteri (Claparede, 1862), пиявки Helobdella stagnalis (Linnaeus, 1758), личинки жуков Yelodes sp., львинки O. viridula, бабочницы D. serotina, комары-звонцы C. melanops, Zavrelimyia sp.

В среднем течении отмечено 55 видов, при этом из Oligochaeta присутствует единственный вид семейства Lumbriculidae, в сравнении с верховьем снизилось разнообразие и доля пиявок при возрастании доли моллюсков, преимущественно брюхоногих. Остается значительной доля жесткокрылых и представителей Tanypodinae из двукрылых. Также среди двукрылых снижается доля и обилие атмосфернодышащих личинок мух-львинок и возрастает доля мух-моллюскоедок (Scyomyzidae), наблюдается рост обилия фитофильных форм Chironominae. Наиболее многочисленными видами были комары-звонцы $X$. falcigera и M. pedellus, менее - брюхоногие P. planorbis, веснянки Leuctra digitata Kempny, 1899, N. cinerea, ручейники B. pullata, O. reticulata, двукрылые Tetanocera ferruginea (Fallen, 1820) и T. pulchra. В низовье ручья обнаружено 66 видов беспозвоночных. Здесь в сравнении с участком среднего течения наблюдалось увеличение разнообразия и обилия пиявок и особенно брюхоногих моллюсков, преимущественно представителей семейства Lymnaeidae. Остается высоким разнообразие и обилие ручейников и жуков, наблюдается рост разнообразия личинок мух-львинок, рост обилия земноводных комаров и мокрецов. Семейство Chironomidae представлено преимущественно представителями Tanypodinae. Чаще других здесь встречались виды брюхоногих L. palustris, P. planorbis, веснянок N. cinerea, ручейников B. pullata, O. reticulata, двукрылых O. viridula, Palpomyia tibialis (Meigen, 1818), Zavrelimyia sp., C. melanops, наиболее многочисленным был вид D. serotina.

Впервые для фауны Центрального Черноземья отмечены 3 вида беспозвоночных: Arrenurus mulleri Koenike, 1901 - палеарктический вид клещей, распространен в Европе, в России известен из ручья на Сахалине [Соколов, 1940], а также из озер, болот, прудов, канав и медленных водотоков в пределах ареала [Тузовский, 1990]; бабочницы (Psychodidae) Satchelliella trivialis (Eaton, 1893) - околоводный убиквист, развивается в прибрежном детрите водоемов, в том числе в болотах, и Ulomyia cognata (Eaton, 1893) - олигосапробный вид, обычно обитающий в прибрежьях и зонах заплеска родников и ручьев.

В сборах также было выявлено 7 редких видов беспозвоночных. К их числу относятся черви Rhynchelmis limosella (Hoffmeister, 1843) - редкий палеарктический вид семейства Lumbriculidae, в ЦЧР отмеченный в болотах Усманского бора в Воронежской области [Силина, Прокин, 2002] и р. Плющань в Липецкой области [Силина, 2014а]. Наибольшее число редких видов выявлено среди ручейников: европейский вид B. pullata, ранее в ЦЧР отмеченный в ручье, впадающем в р. Воргол в Липецкой обл. [Силина, Иванов, Григоренко, 2004] и Воловиковом ручье в долине р. Айдар в Белгородской области [Силина, 2013, 
2014б]; O. reticulata - редкий европейский вид, в России известный из Коми, Карелии и Ленинградской области, в ЦЧР известен из окрестностей биостанции Воронежского государственного университета «Веневитиново» (Воронежская область) и окрестностей Михайловского горно-обогатительного комбината (Курская область, р. Песочная); транспалеарктический вид Molannodes tinctus (Zetterstedt, 1840), основной ареал которого находится в более северных широтах, редок в ЦЧР, где отмечен в окрестностях биостанции «Веневитиново» (Воронежская область) и в р. Ворскла (Белгородская область); а также суператлантический вид Limnephilus ignavus (MacLachlan, 1865), известный из Европы и Средней Азии, в ЦЧР отмечен в родниках и ручьях Липецкой и Воронежской областей и в окрестностях п. Борисовка Белгородской области [Силина, Иванов, Григоренко, 2004].

Среди клопов интерес представляет находка крупного панатлантического вида водомерок Aquarius najas (De Geer, 1773), отмеченного ранее в ЦЧР в окрестностях п. Борисовка (Белгородская область) [Канюкова, Голуб, Прокин, 2002]. Среди двукрылых к редким отнесен вид бабочниц Tonnoriella pulchra (Eaton, 1893) с невыясненным ареалом. В ЦЧР вид впервые был обнаружен в Воловиковом ручье долины р. Айдар (Белгородская область) [Силина, 2013, 2014б].

Результаты исследования представлены в таблице.

Список водных беспозвоночных ручья в урочище Острасьевы яры

(Белгородская область, Борисовский район) по данным 2004-2007 гг.

(2004 г. - сборы А.Е. Силиной, 2005-2007 гг. - сборы Е.Ю. Аникеенко)

The list of aquatic invertebrates of the site Ostrasyevy Yary (Belgorod Region, Borisovsky District) according to the data of 2004-2007

(2004 - collected by A.E. Silina, 2005-2007 - collected by E.Yu. Anikeenko)

\begin{tabular}{|c|c|c|c|c|c|c|c|c|c|c|c|c|c|c|c|}
\hline \multirow{2}{*}{ Таксоны } & \multicolumn{3}{|c|}{$\begin{array}{l}\text { Верхнее } \\
\text { течение }\end{array}$} & \multicolumn{5}{|c|}{ Среднее течение } & \multicolumn{7}{|c|}{ Нижнее течение } \\
\hline & 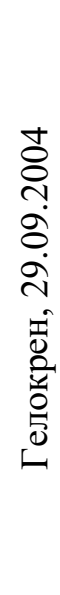 & 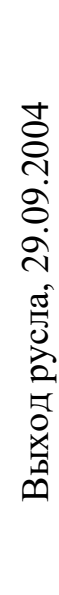 & 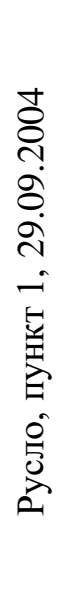 & 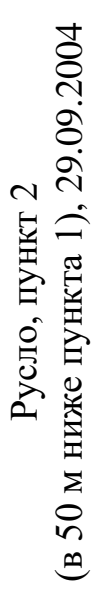 & 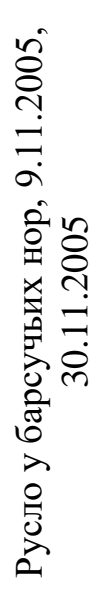 & 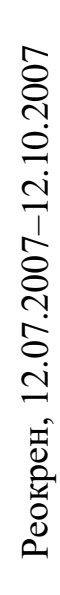 & 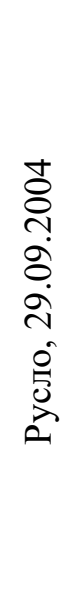 & 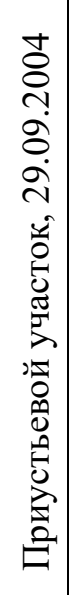 & 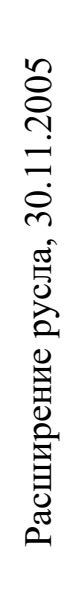 & 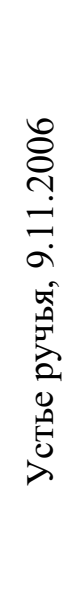 & 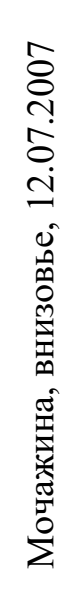 & 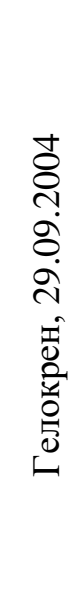 & 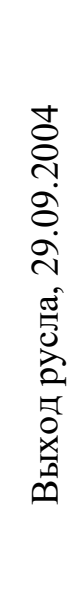 & 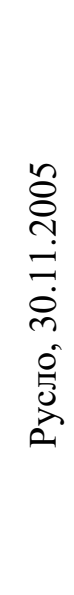 & 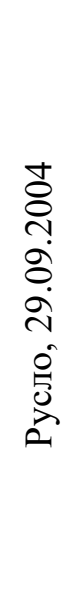 \\
\hline 1 & 2 & 3 & 4 & 5 & 6 & 7 & 8 & 9 & 10 & 11 & 12 & 13 & 14 & 15 & 16 \\
\hline \multicolumn{16}{|l|}{ Gordiacea } \\
\hline Gordius sp. & & & & & & & & & & & & & & & + \\
\hline \multicolumn{16}{|l|}{ Oligochaeta } \\
\hline $\begin{array}{l}\text { Limnodrilus hoff- } \\
\text { meisteri } \\
\text { (Claparede, 1862) }\end{array}$ & & + & & & & & & & & & & & & & \\
\hline $\begin{array}{l}\text { Limnodrilus pro- } \\
\text { fundicola (Verrill, } \\
\text { 1873) }\end{array}$ & & + & & & & & & & & + & & & & & \\
\hline
\end{tabular}


Продолжение таблицы

Continuation of the table

\begin{tabular}{|c|c|c|c|c|c|c|c|c|c|c|c|c|c|c|c|}
\hline 1 & 2 & 3 & 4 & 5 & 6 & 7 & 8 & 9 & 10 & 11 & 12 & 13 & 14 & 15 & 16 \\
\hline $\begin{array}{l}\text { Potamothrix } \\
\text { hammoniensis } \\
\text { (Michaelsen, } \\
\text { 1901) }\end{array}$ & & + & & & & & & & & & & & & & \\
\hline $\begin{array}{l}\text { Psammoryctides } \\
\text { albicola (Michael- } \\
\text { sen, 1901) }\end{array}$ & & & + & & & & & & & & & & & & \\
\hline $\begin{array}{l}\text { Rhynchelmis limo- } \\
\text { sella (Hoffmeister, } \\
1843 \text { ) }\end{array}$ & + & & & & & & & & & & & & & & \\
\hline $\begin{array}{l}\text { Lumbriculus var- } \\
\text { iegatus (Müller, } \\
\text { 1773) }\end{array}$ & & & & + & & & + & + & + & & & + & & & \\
\hline \multicolumn{16}{|l|}{ Hirudinea } \\
\hline $\begin{array}{l}\text { Helobdella stag- } \\
\text { nalis (Linnaeus, } \\
1758 \text { ) }\end{array}$ & + & + & + & & & + & & & & & & & & & \\
\hline $\begin{array}{l}\text { Glossiphonia het- } \\
\text { eroclita (Linnaeus, } \\
1761 \text { ) }\end{array}$ & & + & & & + & & & & & & + & + & + & & \\
\hline $\begin{array}{l}\text { Glossiphonia } \\
\text { complanata } \\
\text { (Linnaeus, 1758) }\end{array}$ & & + & & & & & & & & & & & & & \\
\hline $\begin{array}{l}\text { Erpobdella oc- } \\
\text { toculata (Linnae- } \\
\text { us, 1758) }\end{array}$ & & & & & & & & & & & & & + & & \\
\hline $\begin{array}{l}\text { Erpobdella lineata } \\
\text { (O.F. Müller, } \\
\text { 1774) }\end{array}$ & + & + & & & & & & & & & & & & + & \\
\hline Erpobdella sp. & & & & & & & & & & & & & & & + \\
\hline \multicolumn{16}{|l|}{ Mollusca } \\
\hline \multicolumn{16}{|l|}{ Bivalvia } \\
\hline $\begin{array}{l}\text { Pseudeupera sub- } \\
\text { truncata (Malm, } \\
\text { 1853) }\end{array}$ & & & & + & + & & & & & & & & & & \\
\hline $\begin{array}{l}\text { Pseudeupera arci- } \\
\text { dens (Krivosheina, } \\
\text { 1978) }\end{array}$ & & + & + & & & & + & & + & & & & & & + \\
\hline Euglesa sp. & & & & & & & & & & & & & & & + \\
\hline \multicolumn{16}{|l|}{ Gastropoda } \\
\hline $\begin{array}{l}\text { Lymnaea trun- } \\
\text { catula (Mueller, } \\
1774 \text { ) }\end{array}$ & & & & + & & & & + & & + & & & & & + \\
\hline $\begin{array}{l}\text { Lymnaea gueretin- } \\
\text { iana (Servain, } \\
\text { 1881) }\end{array}$ & & & & & & & & + & & & & + & & & \\
\hline $\begin{array}{l}\text { Lymnaea ovata } \\
\text { (Draparnaud, } \\
\text { 1805) }\end{array}$ & & & & & & & & + & & & & & & & \\
\hline
\end{tabular}


Продолжение таблицы

Continuation of the table

\begin{tabular}{|c|c|c|c|c|c|c|c|c|c|c|c|c|c|c|c|}
\hline 1 & 2 & 3 & 4 & 5 & 6 & 7 & 8 & 9 & 10 & 11 & 12 & 13 & 14 & 15 & 16 \\
\hline $\begin{array}{l}\text { Lymnaea palustris } \\
\text { (Mueller, 1774) }\end{array}$ & & & & & & & & + & & + & & + & + & & + \\
\hline \multicolumn{16}{|l|}{$\begin{array}{l}\text { Lymnaea turricula } \\
\text { (Held, 1836) }\end{array}$} \\
\hline $\begin{array}{l}\text { Lymnaea peregra } \\
\text { (Mueller, 1774) }\end{array}$ & & & & & & & & & & & & + & + & & \\
\hline $\begin{array}{l}\text { Lymnaea callom- } \\
\text { phala (Servain, } \\
\text { 1881) }\end{array}$ & & & & & & & & & & & & + & & & \\
\hline Lymnaea sp. & & & & & & & & & & & + & & & & \\
\hline $\begin{array}{l}\text { Armiger crista } \\
\text { (Linnaeus, 1758) }\end{array}$ & & & & & & & & & & & & & & & + \\
\hline $\begin{array}{l}\text { Planorbis planorbis } \\
\text { (Linnaeus, 1758) }\end{array}$ & & & + & + & & + & + & + & & & + & + & + & + & + \\
\hline $\begin{array}{l}\text { Anisus laevis } \\
\text { (Mueller, 1774) }\end{array}$ & & + & & & & & & & & & & & & & \\
\hline \multicolumn{16}{|l|}{ Crustacea } \\
\hline ?Cyclocypris sp. & & & & + & & & & & & & & & & & \\
\hline \multicolumn{16}{|l|}{ Arachnidia } \\
\hline \multicolumn{16}{|l|}{ Aranei } \\
\hline $\begin{array}{l}\text { Argyroneta aquat- } \\
\text { ica (Clerck, 1757) }\end{array}$ & & & & & & & & & & & & + & & & \\
\hline \multicolumn{16}{|l|}{ Acari } \\
\hline $\begin{array}{l}\text { Arrenurus mulleri } \\
\text { Koenike, } 1901\end{array}$ & & + & & & & & & & & & & & & & \\
\hline \multicolumn{16}{|l|}{ Insecta } \\
\hline \multicolumn{16}{|l|}{ Collembola } \\
\hline $\begin{array}{l}\text { Podura aquatica } \\
\text { Linnaeus, } 1758\end{array}$ & & & & & & & & & & & & & + & & \\
\hline $\begin{array}{l}\text { Isotomurus palus- } \\
\text { tris (Müller, 1776) }\end{array}$ & & & & + & & + & & & & & & & & & \\
\hline \multicolumn{16}{|l|}{ Plecoptera } \\
\hline $\begin{array}{l}\text { Leuctra nigra } \\
\text { Olivier, } 1811\end{array}$ & & & + & & & & & & & & & & & & \\
\hline $\begin{array}{l}\text { Leuctra hyppopus } \\
\text { Kempny, } 1899\end{array}$ & & & + & & & & & & & & & & & & \\
\hline $\begin{array}{l}\text { Leuctra digitata } \\
\text { Kempny, } 1899\end{array}$ & + & & + & + & + & & & & & & & & & & \\
\hline $\begin{array}{l}\text { Nemurella pictetii } \\
\text { Klapalek, } 1900\end{array}$ & & & + & & & & & & & & & & & & \\
\hline $\begin{array}{l}\text { Nemoura cinerea } \\
\text { Retzius, } 1783\end{array}$ & + & + & + & + & + & & & & + & & & & & & \\
\hline $\begin{array}{l}\text { Nemoura flexuosa } \\
\text { Aubert, } 1949\end{array}$ & & & & & & & & & + & & & & & & \\
\hline $\begin{array}{l}\text { Nemoura dubitans } \\
\text { Morton, } 1894\end{array}$ & & & + & & & & & & & & & & & & \\
\hline \multicolumn{16}{|l|}{ Ephemeroptera } \\
\hline $\begin{array}{l}\text { Nigrobaetis digi- } \\
\text { tatus (Bengtsson, } \\
\text { 1913) }\end{array}$ & & & & & & & & & & & & + & & & \\
\hline
\end{tabular}


Продолжение таблицы

Continuation of the table

\begin{tabular}{|c|c|c|c|c|c|c|c|c|c|c|c|c|c|c|c|}
\hline 1 & 2 & 3 & 4 & 5 & 6 & 7 & 8 & 9 & 10 & 11 & 12 & 13 & 14 & 15 & 16 \\
\hline Baetis sp. & & & & & & & & & & & & & + & & \\
\hline \multicolumn{16}{|l|}{ Trichoptera } \\
\hline $\begin{array}{l}\text { Polycentropus } \\
\text { flavomaculatus } \\
\text { (Pictet, 1834) }\end{array}$ & + & & + & & & & & & & & & & & & \\
\hline $\begin{array}{l}\text { Plectrocnemyia } \\
\text { conspersa (Curtis, } \\
1834 \text { ) }\end{array}$ & & & & & & & & & + & & & & & & \\
\hline $\begin{array}{l}\text { Beraea pullata } \\
\text { (Curtis, 1834) }\end{array}$ & & & & + & + & & + & + & + & & & + & + & & + \\
\hline $\begin{array}{l}\text { Erotesis sp. (?bal- } \\
\text { tica MacLachlan, } \\
\text { 1877) }\end{array}$ & & & & & & & & & & & & & + & & \\
\hline Agrypnia sp. & & & & & & & & & + & & & & & & \\
\hline $\begin{array}{l}\text { Oligostomis retic- } \\
\text { ulata (Linnaeus, } \\
1761 \text { ) }\end{array}$ & + & & & + & & & + & + & & & & + & + & & + \\
\hline $\begin{array}{l}\text { Molannodes tinc- } \\
\text { tus (Zetterstedt, } \\
1840 \text { ) }\end{array}$ & + & & + & & & & & & & & & & & & \\
\hline Chaetopteryx sp. & & & & & & & & & & & & + & & & \\
\hline $\begin{array}{l}\text { Limnephilus igna- } \\
\text { vus MacLachlan, } \\
1865\end{array}$ & & & & & & & + & & & & & & & & + \\
\hline \multicolumn{16}{|l|}{ Heteroptera } \\
\hline $\begin{array}{l}\text { Notonecta glauca } \\
\text { Linnaeus, } 1758\end{array}$ & & & & & & + & & & & & & & & & \\
\hline Gerridae sp. & & & & & & + & & & & & & & & & \\
\hline $\begin{array}{l}\text { Aquarius najas } \\
\text { (De Geer, 1773) }\end{array}$ & & & & & & & & & & & & + & & & \\
\hline $\begin{array}{l}\text { Hebrus ruficeps } \\
\text { (Thomson, 1871) }\end{array}$ & & & & & & & + & & & & & & & & \\
\hline \multicolumn{16}{|l|}{ Coleoptera } \\
\hline $\begin{array}{l}\text { Haliplus sibiricus } \\
\text { Motschulsky, } \\
1860\end{array}$ & & & & & & & & & & & & + & & & \\
\hline Haliplus sp. & & & & & & & & + & & & & & & & \\
\hline Elmidae sp. & & + & & & & & & & & & & & & & \\
\hline Ylodes sp. & + & & & + & & & & & & & & & & & \\
\hline Scirtes sp. & & & & + & & & & & & & & & & & \\
\hline Scirtidae sp. & & & & & & & & + & & & & & & & \\
\hline $\begin{array}{l}\text { Noterus clavicor- } \\
\text { nis (De Geer, } \\
1774)\end{array}$ & & & & & & & & & & & & + & & + & \\
\hline Platambus sp. & & + & & & & & & & & & & & & & \\
\hline $\begin{array}{l}\text { Laccobius minutus } \\
\text { (Linnaeus, 1758) }\end{array}$ & & & & & & & & & & & & + & & & \\
\hline $\begin{array}{l}\text { Hydroglyphus } \\
\text { geminus (F., 1792) }\end{array}$ & & & & & & & & & & & & + & & & \\
\hline
\end{tabular}


Продолжение таблицы Continuation of the table

\begin{tabular}{|c|c|c|c|c|c|c|c|c|c|c|c|c|c|c|c|}
\hline 1 & 2 & 3 & 4 & 5 & 6 & 7 & 8 & 9 & 10 & 11 & 12 & 13 & 14 & 15 & 16 \\
\hline $\begin{array}{l}\text { Anacaena } \\
\text { lutescens (Ste- } \\
\text { phens, } 1829)\end{array}$ & & & & & & & + & & & & & + & & & \\
\hline $\begin{array}{l}\text { Ilybius fuliginosus } \\
\text { (Fabricius, 1792) }\end{array}$ & & & & & & & & & & & & + & & + & \\
\hline Ilybius sp.1 & & & & + & & & & & & & & & + & & \\
\hline Ilybius sp.2 & & & & & & & & + & & & & & & & \\
\hline $\begin{array}{l}\text { Agabus bipustula- } \\
\text { tus (Linnaeus, } \\
\text { 1767) }\end{array}$ & & & & & & & & & & & & + & & & \\
\hline Dytiscidae sp. & & & + & & & & & & & & & & & & \\
\hline Dytiscidae sp.1 & & & + & & & & & & & & & & & & \\
\hline Dytiscidae sp.2 & & & + & & & & & & & & & & & & \\
\hline Dytiscidae sp.3 & & & + & & & & & & & & & & & & \\
\hline $\begin{array}{l}\text { Hydrobius fusci- } \\
\text { pes (Linnaeus, } \\
1758 \text { ) }\end{array}$ & & & & & & & & + & & & & & & & \\
\hline Hydrophilidae sp. & & & & & & & & & & & & & + & & \\
\hline \multicolumn{16}{|l|}{ Diptera } \\
\hline \multicolumn{16}{|c|}{ Brachycera } \\
\hline \multicolumn{16}{|c|}{ Stratiomyidae } \\
\hline $\begin{array}{l}\text { Oplodontha virid- } \\
\text { ula (Fabricius, } \\
1775 \text { ) }\end{array}$ & + & + & & + & & & & + & & & & + & + & + & \\
\hline $\begin{array}{l}\text { Odonthomyia ti- } \\
\text { grina (Fabricius, } \\
\text { 1775) }\end{array}$ & & & & & & & & & & & & & + & & \\
\hline $\begin{array}{l}\text { Odontomyia angu- } \\
\text { lata (Pancer, } \\
[1898])\end{array}$ & & & & & & & & & & & & & + & & \\
\hline $\begin{array}{l}\text { Stratiomys cha- } \\
\text { maeleon (L., } \\
1758 \text { ) }\end{array}$ & & & & & & & & & & & & + & & & \\
\hline $\begin{array}{l}\text { Stratiomys longi- } \\
\text { cornis (Scopoli, } \\
1763 \text { ) }\end{array}$ & & & & & & + & & & & & & & + & & \\
\hline $\begin{array}{l}\text { Stratiomys singu- } \\
\text { larior (Harris, } \\
{[1776] \text { ) }}\end{array}$ & & & & & & & & & & & & & + & & \\
\hline \multicolumn{16}{|l|}{ Tabanidae } \\
\hline $\begin{array}{c}\text { Hybomitra bimac- } \\
\text { ulata (Macquart, } \\
\text { 1826) }\end{array}$ & + & & & & & & & & & & & & & & \\
\hline Crhysops sp. & & & & & & & + & & & & & & & & \\
\hline \multicolumn{16}{|l|}{ Syrphidae } \\
\hline $\begin{array}{l}\text { Sericomyia lap- } \\
\text { pona (Linnaeus, } \\
1758 \text { ) }\end{array}$ & & & + & & & & & & & & & & & & \\
\hline \multicolumn{16}{|l|}{ Ephydridae } \\
\hline Parydra sp. & + & & & & & & & & & & & & & & \\
\hline Hydrellia sp. & & & & & & & & + & & & & + & & & \\
\hline
\end{tabular}


Продолжение таблицы

Continuation of the table

\begin{tabular}{|c|c|c|c|c|c|c|c|c|c|c|c|c|c|c|c|}
\hline 1 & 2 & 3 & 4 & 5 & 6 & 7 & 8 & 9 & 10 & 11 & 12 & 13 & 14 & 15 & 16 \\
\hline \multicolumn{16}{|l|}{ Sciomyzidae } \\
\hline $\begin{array}{l}\text { Pteromicra agustipen- } \\
\text { nis (Staeger, 1845) }\end{array}$ & & & & & & & & & & & & + & & & \\
\hline $\begin{array}{l}\text { Tetanocera ferru- } \\
\text { ginea Fallen, } 1820\end{array}$ & & & & & & & + & + & & & & + & + & & \\
\hline \multicolumn{16}{|l|}{ Muscidae } \\
\hline Lispe sp. & & & & & & & + & & & & & & + & & \\
\hline \multicolumn{16}{|l|}{ Nematocera } \\
\hline \multicolumn{16}{|c|}{ Ptychopteridae } \\
\hline $\begin{array}{l}\text { Ptychoptera } \\
\text { comtaminata } \\
\text { (Linnaeus, 1758) }\end{array}$ & & + & + & & & & + & & & & & & & & \\
\hline \multicolumn{16}{|l|}{ Limoniidae } \\
\hline $\begin{array}{l}\text { Helius longirostris } \\
\text { (Meigen, } 1818 \text { ) }\end{array}$ & & & & & + & & & & & & + & & + & + & \\
\hline $\begin{array}{l}\text { Limnophila } \\
\text { schranki Ooster- } \\
\text { broek, } 1992\end{array}$ & + & & & & & & & & & & & & & & \\
\hline $\begin{array}{l}\text { Pseudolimnophila } \\
\text { lucorum (Meigen, } \\
\text { 1818) }\end{array}$ & + & + & & & & & & & + & & & & & & \\
\hline $\begin{array}{l}\text { Eleophila sub- } \\
\text { marmorata (Ver- } \\
\text { rall, 1887) }\end{array}$ & + & + & & & & & + & & + & + & & & & & \\
\hline \multicolumn{16}{|l|}{ Sciaridae } \\
\hline ?Bradisia sp. & & & & & & & & & & + & & & & & \\
\hline \multicolumn{16}{|l|}{ Psichodidae } \\
\hline $\begin{array}{l}\text { Satchelliella trivi- } \\
\text { alis (Eaton, 1893) }\end{array}$ & + & & + & & + & & + & & & & & + & & & \\
\hline $\begin{array}{l}\text { Tonnoriella pul- } \\
\text { chra (Eaton, 1893) }\end{array}$ & + & + & & + & & & + & & & & & & & & \\
\hline $\begin{array}{l}\text { Ulomyia cognata } \\
\text { (Eaton, 1893) }\end{array}$ & + & + & & + & & & & & & & & & & & \\
\hline \multicolumn{16}{|l|}{ Dixidae } \\
\hline $\begin{array}{l}\text { Dixa nebulosa } \\
\text { (Meigen, 1830) }\end{array}$ & & & & + & & & & & & & & & & & \\
\hline $\begin{array}{l}\text { Dixella serotina } \\
\text { (Meigen, 1818) }\end{array}$ & & & + & & & & & + & & & & + & + & & \\
\hline \multicolumn{16}{|l|}{ Culicidae } \\
\hline Aedes sp. & & & & & & & & & & & & & & + & \\
\hline $\begin{array}{l}\text { Anopheles macu- } \\
\text { lipennis (Meigen, } \\
\text { 1818) }\end{array}$ & & & & & & & & + & & & & & & & \\
\hline \multicolumn{16}{|l|}{\begin{tabular}{|r|} 
Simuliidae \\
\end{tabular}} \\
\hline $\begin{array}{l}\text { Nevermannia } \\
\text { latigonia (Rubzov, } \\
\text { 1956) }\end{array}$ & & & + & & & & & & & & & & & & \\
\hline \multicolumn{16}{|c|}{\begin{tabular}{|c|} 
Ceratopoginidae \\
\end{tabular}} \\
\hline $\begin{array}{l}\text { Palpomyia brachy- } \\
\text { alis (Haliday, 1833) } \\
\text { (=P. longipennis } \\
\text { (Kieffer, 1919)) }\end{array}$ & & & & & & & & & & & & & + & & \\
\hline
\end{tabular}


Окончание таблицы End of the table

\begin{tabular}{|c|c|c|c|c|c|c|c|c|c|c|c|c|c|c|c|}
\hline 1 & 2 & 3 & 4 & 5 & 6 & 7 & 8 & 9 & 10 & 11 & 12 & 13 & 14 & 15 & 16 \\
\hline $\begin{array}{l}\text { Palpomyia tibialis } \\
\text { (Meigen, 1818) }\end{array}$ & & & & & & & & & & & & + & & & \\
\hline
\end{tabular}
Chironomidae

\section{Apsectrotanypus} trifascipennis

(Zetterstedt, 1838)

Natarsia punctata

(Fabricius, 1805)

Macropelopia sp.

Conchapelopia

melanops

(Wiedemann,

1818)

Xenopelopia falcigera (Kieffer,

1911)

Zavrelimyia sp.

Procladius cho-

reus Meigen,

1804

Procladius ferrugineus Kieffer,

1919

Prodiamesa olivacea (Meigen,

1818)

Parametriocnemus stylatus Kieffer, 1924

Chaetocladius sp.

Chironomus uliginosus Keyl, 1960

Chironomus sp.

Polypedilum bicrenatum Kieffer, 1921

Polypedilum gr.convictum

Polypedilum scalaenum

(Schrank, 1803)

Paratendipes albimanus (Meigen, + 1818)

Microtendipes pedellus (De Geer, 1776)

Tanytarsus excavatus Edwards, 1929

Micropsectra viridiscutellata Goetghebuer, 1931

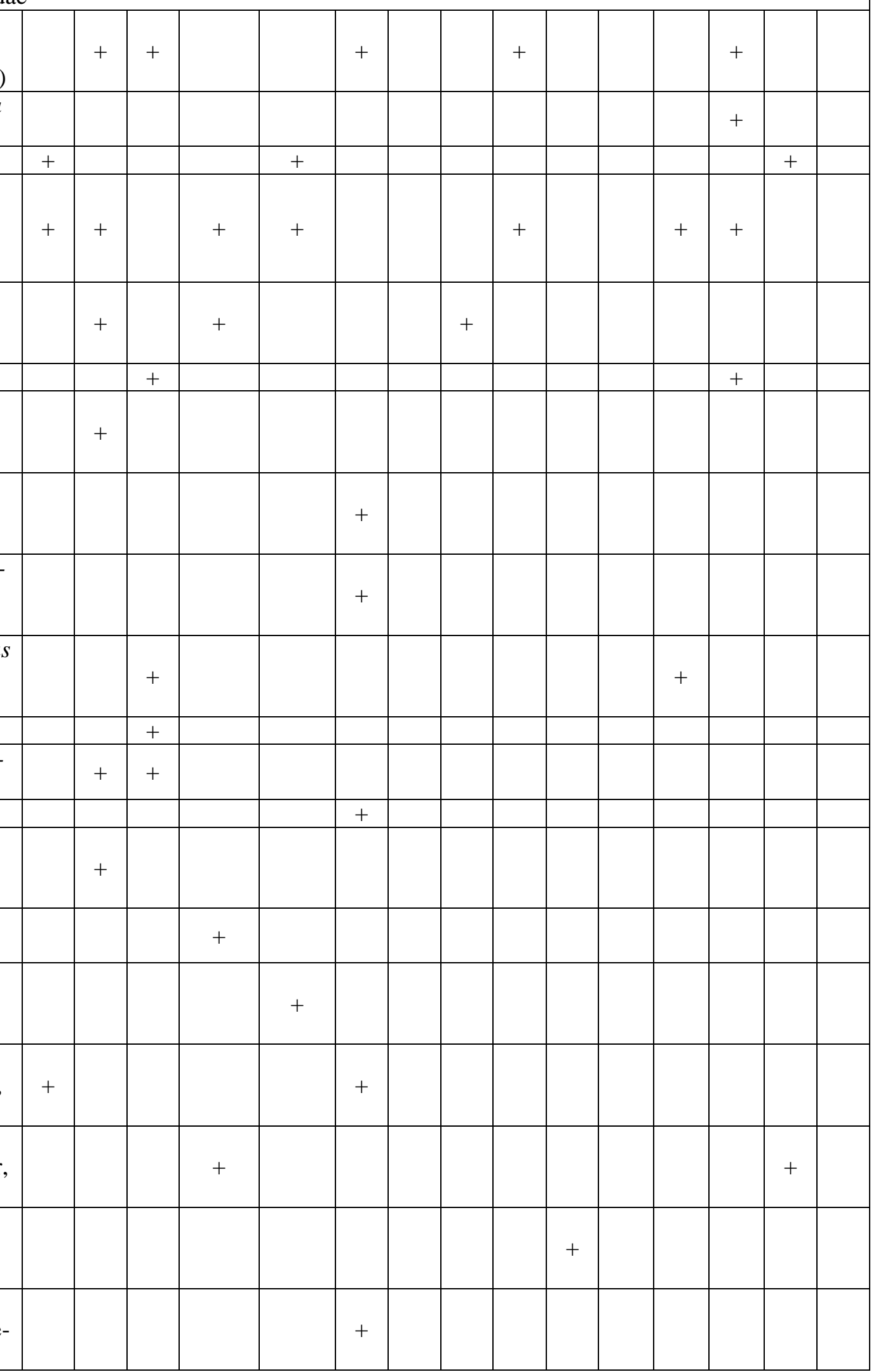




\section{Заключение}

В результате исследований в ручьевой экосистеме участка «Острасьевы яры» выявлено 135 видов беспозвоночных, из них в верховье - 53 вида, в среднем течении - 53, в низовье - 66. Доминировали насекомые, составившие 68,3 \% от числа собранных животных, среди которых наиболее массовыми были двукрылые и веснянки. Массовыми видами являлись моллюски $P$. arcidens и веснянки N. cinerea. Выявлены широко распространенные и редкие виды.

Впервые для фауны Центрального Черноземья указаны 3 вида беспозвоночных: клещи A. mulleri и бабочницы S. trivialis и U. cognata.

Полученные данные могут быть использованы в качестве фоновых при оценке зоогенного влияния на макрозообентос родниково-ручьевой экосистемы.

Авторы выражают глубокую благодарность к.б.н. А.А. Прокину (ИБВВ РАН, Ярославская обл., п. Борок) за проверку определения трудноидентифицируемых видов клопов и жуков. Также авторы признательны за помощь в организации экспедиций дирекции и сотрудникам заповедника «Белогорье».

\section{Список литературы}

1. Ивановский А.А. 2010. Типы сообществ макрозообентоса в родниках Пензенской области. Вестник Московского государственного областного университета. Естественные науки, 3: 72-79.

2. Канюкова Е.В., Голуб В.Б., Прокин А.А. 2002. Обзор водных полужесткокрылых и водомерок (Heteroptera) фауны среднерусской лесостепи. Евразиатский энтомологический журнал, 1 (2): 185-196.

3. Определитель пресноводных беспозвоночных России и сопредельных территорий. 1994. T. 1. Низшие беспозвоночные: Губки, Книдарии, Турбеллярии, Коловратки, Гастротрихи, Нематоды, Волосатики, Олигохеты, Пиявки, Мшанки, Тихоходки. СПб., Наука, 396 с.

4. Определитель пресноводных беспозвоночных России и сопредельных территорий. 1997. T. 3. Паукообразные и низшие насекомые: Акариды, Орибатиды, Галакариды, Гидрахниды, Пауки, Ногохвостки, Поденки, Веснянки, Стрекозы, Клопы. СПб., Наука, 448 с.

5. Определитель пресноводных беспозвоночных России и сопредельных территорий. 1999. T. 4. Высшие насекомые: Двукрылые насекомые (Комары, Мухи). СПб., Наука, 1000 с.

6. Определитель пресноводных беспозвоночных России и сопредельных территорий. 2001. T. 5. Высшие насекомые: Ручейники, Бабочки, Жуки, Большекрылые, Сетчатокрылые. СПб., Наука, 836 с.

7. Определитель пресноводных беспозвоночных России и сопредельных территорий. 2004. Т. 6. Моллюски, Полихеты, Немертины. СПб., Наука, 528 с.

8. Решетникова Н.М. 2018. Примеры влияния бобров на флору хорошо изученных охраняемых территорий. $B$ кн.: Труды Государственного природного заповедника «Рдейский». T. 4. Бобры в заповедниках европейской части России. Великие Луки, Великолукская типография: 364-382.

9. Силина А.Е. 2013. Амфибиотические насекомые (Insecta) водоемов природного парка «Ровеньский». B кн.: Гидроэнтомология в России и сопредельных странах. Материалы $\mathrm{V}$ Всероссийского симпозиума по амфибиотическим и водным насекомым. ИБВВ им. И.Д. Папанина РАН. Ярославль, Филигрань: 166-178.

10. Силина А.Е. 2014а. Макрозообентос реки Плющань. В кн.: Природа Плющани. Воронеж, Научная книга: 169-194.

11. Силина А.Е. 2014б. Фауна беспозвоночных родников и ручьев природного парка «Ровеньский» в Белгородской области. $B$ кн.: Современные проблемы особо охраняемых 
природных территорий регионального значения и пути их решения. Материалы Межрегиональной научно-практической конференции (г. Воронеж, 18 декабря 2014 г.). Воронеж, ВГУ: 232-243.

12. Силина А.Е., Иванов В.Д., Григоренко В.Н. 2004. Список ручейников (Trichoptera) Центрального Черноземья России и сопредельных территорий. $B$ кн.: Фауна, вопросы экологии, морфологии и эволюции амфибиотических и водных насекомых России. Материалы II Всероссийского симпозиума по амфибиотическим и водным насекомым (г. Воронеж, 1517 сентября 2003 г.). Воронеж, ВГУ: 165-196.

13. Силина А.Е., Прокин А.А. 2002. Донная макрофауна болота Клюквенное-1 в Усманском бору. $B$ кн.: Труды лаборатории биоразнообразия и мониторинга наземных и водных экосистем Среднерусской лесостепи: сектор гидробиологического мониторинга. Т. 1. Гидробиологические исследования водоемов Среднерусской лесостепи. Воронеж, ВГУ: 151-220.

14. Соколов И.И. 1940. Фауна СССР. Паукообразные. Т. V. Вып. 2. Hydracarina - Водяные клещи. М.-Л., Наука, 511 с.

15. Тузовский П.В. 1990. Определитель дейтонимф водяных клещей. М., Наука, 238 с.

16. Чертопруд М.В. 2006. Родниковые сообщества макробентоса Московской области. Журнал общей биологии, 67 (5): 376-384.

17. Чужекова Т.А. 2015. Межгодовые изменения структуры макрозообентоса родниковых ручьев бассейна Средней Волги в условиях антропогенной нагрузки. Биология внутренних вод. 3: 39-48. (Chuzhekova T.A. 2015. Dynamics of macrozoobenthos structure in urban spring brooks of the Middle Volga basin. Inland Water Biology, 3: 39-48.)

\section{References}

1. Ivanovskij A.A. 2010. Tipy soobshchestv makrozoobentosa v rodnikah Penzenskoj oblasti [Types of macrozoobenthos communities in the springs of the Penza Region]. Vestnik Moskovskogo gosudarstvennogo oblastnogo universiteta. Yestestvennyye nauki, 3: 72-79.

2. Kanyukova E.V., Golub V.B., Prokin A.A. 2002. A Review of Water and Semi-aquatic Bugs (Heteroptera) of the Fauna of the Forest-steppe of European Russia. Euroasian Entomological journal, 1 (2): 185-196 (in Russian).

3. Opredelitel' presnovodnykh bespozvonochnykh Rossii i sopredel'nykh territoriy [Keys to freshwater invertebrates of Russia and adjacent territories]. 1994. Vol. 1. Nizshie bespozvonochnye: Gubki, Knidarii, Turbellyarii, Kolovratki, Gastrotrikhi, Nematody, Volosatiki, Oligokhety, Piyavki, Mshanki, Tikhokhodki [Lower invertebrates: Sponges, Cnidaria, Turbellaria, Rotifers, Gastrotrichs, Nematodes, Hairworms, Oligochaetes, Leeches, Bryozoans, Tardigrades]. Saint-Petersburg, Publ. Nauka, 396 p.

4. Opredelitel' presnovodnykh bespozvonochnykh Rossii i sopredel'nykh territoriy [Keys to freshwater invertebrates of Russia and adjacent territories]. 1997. Vol. 3. Paukoobraznye i nizshie nasekomye: Akaridy, Oribatidy, Galakaridy, Gidrakhnidy, Pauki, Nogokhvostki, Podenki, Vesnyanki, Strekozy, Klopy [Arachnids and lower insects: Acarids, Oribatids, Galacarids, Hydrachnids, Spiders, Legs, Mayflies, Vesnianki, Dragonflies, Bedbugs]. Saint-Petersburg, Publ. Nauka, 448 p.

5. Opredelitel' presnovodnykh bespozvonochnykh Rossii i sopredel'nykh territoriy [Keys to freshwater invertebrates of Russia and adjacent territories]. 1999. Vol. 4. Vysshie nasekomye: Dvukrylye nasekomye (Komary, Mukhi) [Higher insects: Diptera insects (Mosquitoes, Flies)]. Saint-Petersburg, Publ. Nauka, 1000 p.

6. Opredelitel' presnovodnykh bespozvonochnykh Rossii i sopredel'nykh territoriy [Keys to freshwater invertebrates of Russia and adjacent territories]. 2001. Vol. 5. Vysshie nasekomye: Rucheyniki, Babochki, Zhuki, Bol'shekrylye, Setchatokrylye [Higher insects: Caddis flies, Butterflies, Beetles, Megaloptera, Neuroptera]. Saint-Petersburg, Publ. Nauka, 836 p.

7. Opredelitel' presnovodnykh bespozvonochnykh Rossii i sopredel'nykh territoriy [Keys to freshwater invertebrates of Russia and adjacent territories]. 2004. Vol. 6. Mollyuski, Polikhety, Nemertiny [Molluscs, Polychaetes, Nemertines]. Saint-Petersburg, Publ. Nauka, 528 p.

8. Reshetnikova N.M. 2018. Primery vliyaniya bobrov na floru khorosho izuchennykh okhranyaemykh territoriy [Examples of the influence of beavers on the flora of well-studied protected areas]. In: Trudy Gosudarstvennogo prirodnogo zapovednika «Rdeyskiy». T. 4. Bobry v zapovednikakh evropeyskoy chasti Rossii. [Proceedings of the State Natural Reserve "Rdeyskiy". Vol. 4. Beavers in the reserves of the European part of Russia]. Velikie Luki, Velikolukskaya tipografiya: 364-382. 
9. Silina A.E. 2013. Amphibiotic Insects (Insecta) of Reservoirs of the Rovensky Nature Park. In: Hydroentomology in Russia and adjacent countries: Materials of the Fifth All-Russia Symposium on Amphibiotic and Aquatic Insects. Yaroslavl, Publ. Filigran: 166-178 (in Russian).

10. Silina A.E. 2014a. Makrozoobentos reki Plyushchan' [Macrozoobenthos of the Plushan river] In: Priroda Plyushchani [Nature Plyuschan]. Voronezh, Publ. Nauchnaya kniga: 169-194.

11. Silina A.E. 20146. Fauna bespozvonochnykh rodnikov i ruch'ev prirodnogo parka «Roven'skiy» v Belgorodskoy oblasti [Fauna of invertebrate springs and streams of the Rovensky Natural Park in the Belgorod Region]. In: Sovremennye problemy osobo okhranyaemykh prirodnykh territoriy regional'nogo znacheniya i puti ikh resheniya [Modern problems of specially protected natural areas of regional importance and ways to solve them]. Materials of the Interregional Scientific and Practical Conference (Voronezh, December 18, 2014). Voronezh, Publ. Voronezh State University: 232-243.

12. Silina A.E., Ivanov V.D., Grigorenko V.N. 2004. Spisok rucheynikov (Trichoptera) Tsentral'nogo Chernozem'ya Rossii i sopredel'nykh territoriy [List of caddisflies (Trichoptera) of the Central Black Earth Region of Russia and adjacent territories]. In: Fauna, voprosy ekologii, morfologii i evolyutsii amfibioticheskikh i vodnykh nasekomykh Rossii [Fauna, questions of ecology, morphology and evolution of amphibiotic and aquatic insects in Russia]. Materials of the II All-Russian Symposium on Amphibiotic and Aquatic Insects (Voronezh, September 15-17, 2003). Voronezh, Publ. Voronezh State University: 165-196.

13. Silina A.E., Prokin A.A. 2002. Donnaya makrofauna bolota Klyukvennoe-1 v Usmanskom boru [Bottom macrofauna of the Klyukvennoye-1 bog in Usmansky pine forest]. In: Trudy laboratorii bioraznoobraziya i monitoringa nazemnykh i vodnykh ekosistem Srednerusskoy lesostepi: sektor gidrobiologicheskogo monitoringa. T. 1. Gidrobiologicheskiye issledovaniya vodoyemov Srednerusskoy lesostepi [Proceedings of the laboratory of biodiversity and monitoring of terrestrial and aquatic ecosystems of the Central Russian forest-steppe: sector of hydrobiological monitoring. Vol. 1. Hydrobiological studies of reservoirs of the Central Russian forest-steppe]. Voronezh, Publ. Voronezh State University: 151-220.

14. Sokolov I.I. 1940. Fauna SSSR. Paukoobraznyye. T. V. Vyp. 2. Hydracarina - Vodyanyye kleshchi [Fauna of the USSR. Arachnids. Vol. V. Iss. 2. Hydracarina - Water mites]. MoscowLeningrad, Publ. Nauka, 511 p.

15. Tuzovskiy P.V. 1990. Opredelitel' deytonimf vodyanykh kleshchey [Keys to the deutonymphs of water mites]. Moscow, Publ. Nauka, 238 p.

16. Chertoprud M.V. 2006. Spring macrobenthos communities of the Moscow province. Zhurnal Obshchei Biologii, 67 (5): 376-384 (in Russian).

17. Chuzhekova T.A. 2015. Dynamics of macrozoobenthos structure in urban spring brooks of the Middle Volga basin. Inland Water Biology, 3: 39-48.

\section{ИНФОРМАЦИЯ ОБ АВТОРАХ}

Силина Алла Евгеньевна, старший научный сотрудник государственного природного заповедника «Белогорье», п. Борисовка, Белгородская обл., Россия

Будаева Ирина Александровна, кандидат биологических наук, доцент, доцент кафедры зоологии и паразитологии медикобиологического факультета Воронежского государственного университета, г. Воронеж, Россия

Аникеенко Елена Юрьевна, заместитель директора по просветительской работе государственного природного заповедника «Белогорье», п. Борисовка, Белгородская обл., Россия

\section{INFORMATION ABOUT THE AUTHORS}

Alla E. Silina, Senior Researcher of Belogorye State Nature Reserve, Borisovka vill., Belgorod Region, Russia

Irina A. Budaeva, Candidate of Biological Sciences, Associate Professor, Associate Professor of Department of Zoology and Parasitology of Faculty of Medicine and Biology of Voronezh State University, Voronezh, Russia

Elena Yu. Anikeenko, Deputy Director for Educational Activities of Belogorye State Nature Reserve, Borisovka vill., Belgorod Region, Russia 